\title{
Ten year follow up of patients referred for coronary artery bypass grafting from a single district general hospital
}

\author{
A J Bathgate, J B Irving
}

\begin{abstract}
Objective-To determine the status of patients 10 years after referral for coronary artery bypass graft (CABG) surgery.

Design-Retrospective analysis of case notes from all patients referred between 1 April 1981 and 31 March 1985. Full information gathered from hospital notes, GP records, and Registrar General for Scotland.

Setting-District General Hospital, West Lothian, Scotland.

Patients-102 patients referred for CABG during study period. Cardiac surgery was undertaken in Brompton Hospital, London, Royal Infirmary, Edinburgh, and Western Infirmary, Glasgow.

Results-At 10 years after operation 32 patients had died ( 27 cardiac, five noncardiac causes). Full data were not available for five patients. Of the 65 remaining patients 24 had no angina, 13 had had a repeat procedure (CABG or angioplasty), and 28 had angina.

Conclusions-Long term benefits of CABG surgery is disappointing. Further steps are required to reduce progression of disease in this population.

(Heart 1997;78:584-586)
\end{abstract}

Keywords: coronary artery bypass surgery; repeat procedure; survival; audit

Although coronary artery bypass graft (CABG) surgery has been accepted treatment for angina pectoris for 25 years few assessments of long term benefit have been available. Evidence from trials ${ }^{1}$ suggested improved survival in triple vessel and left main disease. How such trials relate to normal practice is uncertain. Hence this audit looked at experience of a single cardiologist in a district general hospital, referring to several surgical centres.

Department of Cardiology, St John's Hospital, Livingston, West Lothian, UK

Correspondence to: $\mathrm{Dr}$ Bathgate, CLDD, Royal Infirmary of Edinburgh, Lauriston Place, Edinburgh EH3 9YW, UK

Accepted for publication 28 August 1997

\section{Methods}

Records of all patients referred for CABG from a district general hospital in West Lothian between 1 April 1981 and 31 March 1985 were retrieved. The following information was collected; sex, age at operation, preoperative angina severity score (according to the Canadian Cardiovascular Society classification), exercise tolerance test results, angiography details including left ventricular function, and preoperative cholesterol concentrations. The details of the operation were also obtained. Outcome of the operation was obtained from the medical notes, Registrar General for deaths, and correspondence with general practitioners/other colleagues. Outcome measures used were; cardiac/non-cardiac deaths, repeat revascularisation procedure, and present anginal status including number of antianginal medications.

Statistical methods used were estimations of the difference between the means stated.

\section{Results}

All the notes of the 102 patients were retrieved, but up to date information on five patients could not be obtained. Therefore 97 patients were included in this report. Eighty seven patients were male and 10 were female. The youngest age at time of operation was 29 years and the oldest was 68 years. One patient who later died of myeloma was operated on as an emergency and did not have angiography.

The results in tables 1 and 2 show the preoperative angiographic details and how they relate to exercise tolerance tests and angina severity. It was found that 43 of the 97 patients did not receive an exercise tolerance test, this

Table 1 Exercise tolerance test score in relation to coronary angiography

\begin{tabular}{lrrrrr}
\hline \multirow{2}{*}{$\begin{array}{l}\text { Exercise tolerance } \\
\text { test }\end{array}$} & \multicolumn{5}{l}{ Coronary angiography } \\
\cline { 2 - 6 } & $1 V$ & $2 V$ & $3 V$ & $L M$ & Total \\
\hline Minor work & 1 & 11 & 17 & 5 & 34 \\
Moderate work & 0 & 1 & 2 & 0 & 3 \\
Major work & 2 & 4 & 8 & 1 & 15 \\
Negative & 0 & 0 & 1 & 1 & 2 \\
Not done & 2 & 19 & 19 & 2 & 42
\end{tabular}

Minor work, ST depression $>2 \mathrm{~mm}$ at heart rate $<120$ beats/ min; Moderate work, ST depression $>2 \mathrm{~mm}$ at heart rate 120 140 beats/min; Major work, ST depression $>2 \mathrm{~mm}$ at heart rate $>140$ beats $/ \mathrm{min}$.

$1 \mathrm{~V}$, one vessel disease; $2 \mathrm{~V}$ two vessel disease; $3 \mathrm{~V}$, three vessel disease; LM left main.

Table 2 Angina severity scores in relation to coronary angiography

\begin{tabular}{llrlll}
\hline \multirow{2}{*}{$\begin{array}{l}\text { Angina severity } \\
\text { scores (CCS) }\end{array}$} & \multicolumn{5}{l}{ Coronary angiography } \\
\cline { 2 - 6 } & $1 V$ & $2 V$ & $3 V$ & $L M$ & Total \\
\hline II & 0 & 6 & 9 & 3 & 18 \\
III & 2 & 22 & 28 & 4 & 56 \\
IV & 3 & 7 & 10 & 2 & 22 \\
Total & 5 & 35 & 47 & 9 & \\
\hline
\end{tabular}

CCS, Canadian Cardiovascular Society angina severity score; $1 \mathrm{~V}$, one vessel disease; $2 \mathrm{~V}$ two vessel disease; $3 \mathrm{~V}$, three vessel disease; LM left main. 


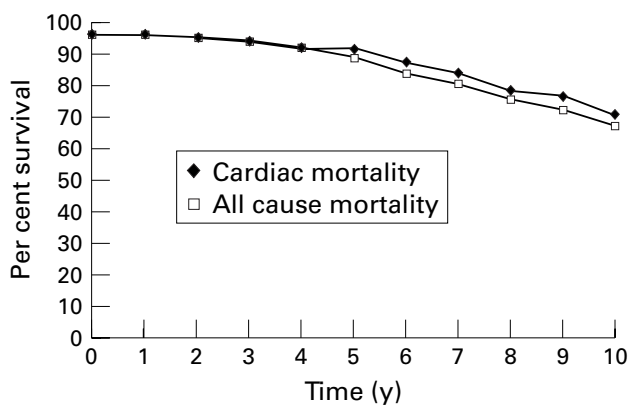

Figure 1 Survival curve of the patients referred for $C A B G$.

included all 10 female patients. The number of patients who had their cholesterol values checked preoperatively was $14(14 \%)$.

Four of eight single grafts done were left internal mammary arteries. One operation included an aneurysmectomy.

To date 43 patients have died ( 40 male and three female). Thirty six of the 43 deaths were cardiac related. The other seven died of stroke (3), renal cell carcinoma (2), myeloma (1), and metastatic carcinoma (1). Eleven patients died in the 11th and 12th year of follow up (nine cardiac deaths). These patients will be regarded as survivors for the purposes of outcome at 10 years. Figure 1 shows the survival curve.

Table 3 Ages of surviving patients and those who died from cardiac causes

\begin{tabular}{lcc}
\hline Age at operation (years) & Survivor & Cardiac death \\
\hline$<30$ & 1 & 0 \\
$30-39$ & 4 & 0 \\
$40-49$ & 12 & 5 \\
$50-59$ & 40 & 13 \\
$60-69$ & 8 & 9 \\
Mean (SEM) & $53.2(1.0)$ & $54.7(1.7)^{\star}$ \\
\hline
\end{tabular}

$\star_{\text {not significant. }}$

Table 4 Exercise tolerance test scores of surviving patients and those who died from cardiac causes

\begin{tabular}{lcc}
\hline Exercise tolerance test score & Survivor & Cardiac death \\
\hline Minimum & 22 & 10 \\
Moderate & 3 & 0 \\
Major & 14 & 2 \\
Negative & 0 & 2 \\
Not done & 26 & 13 \\
\hline
\end{tabular}

Table 5 Angiographic details and operations of surviving patients and those who died from cardiac causes

\begin{tabular}{lcc}
\hline & Survivor & Cardiac death \\
\hline Number of vessels affected & 5 & 0 \\
1 & 26 & 8 \\
2 & 28 & 16 \\
3 & 6 & 3 \\
Left main & $2.45(0.09)$ & $2.81(0.11)^{\star}$ \\
Mean (SEM) & \\
Left ventricular function & 38 & 11 \\
Normal & 22 & 10 \\
Mild & 4 & 2 \\
Moderate & 1 & 4 \\
Poor & 8 & 0 \\
Number of grafts placed during operation & \\
1 & 14 & 4 \\
2 & 29 & 13 \\
3 & 14 & 10 \\
$>3$ & $2.78(0.12)$ & $3.37(0.19)^{\star \star}$ \\
Mean $($ SEM) & &
\end{tabular}

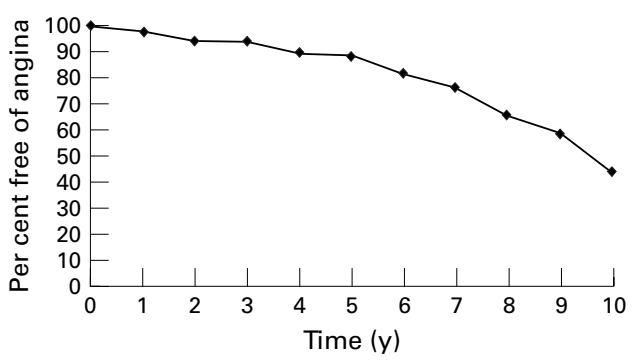

Figure 2 Percentage of survivors free from angina when year of symptom return is known.

Table 7 Number of grafts placed at operation and the mean age at operation for the three outcome groups

\begin{tabular}{lllc}
\hline $\begin{array}{l}\text { Number of } \\
\text { grafts }\end{array}$ & No angina & $\begin{array}{l}\text { Repeat } \\
\text { procedure }\end{array}$ & Angina \\
\hline 1 & 2 & 3 & 2 \\
2 & 8 & 5 & 1 \\
3 & 8 & 3 & 18 \\
$>3$ & 6 & 2 & 7 \\
Mean age & $53.4 \dagger$ & $46.3^{\star}$ & $53.6 \dagger$ \\
\hline
\end{tabular}

${ }^{\star} \mathrm{p}<0.05 ;$ †not significant.

Tables 3-5 outline the age, exercise tolerance test scores, angiographic details, and operation undergone of the 65 surviving patients as well as those who died a cardiac death.

The outcome of the 65 survivors was that 24 of them had no angina, 13 had a repeat procedure performed (either angioplasty or repeat surgery), and 28 had angina. Table 6 shows the number of years after the operation when patients experienced angina. Figure 2 shows the percentage of survivors free from angina when the year of symptom return is known. Twenty one of 28 survivors with angina were taking at least two regular anti-anginal drugs.

The original number of grafts placed at operation are shown for the three outcome groups-those without angina, those who received repeat procedure, and those with angina. The mean ages for the three outcome groups are also shown (table 7).

\section{Discussion}

To refer a patient for coronary artery bypass surgery is not a decision taken lightly. The outcome of the operation itself has improved considerably since its inception in the 1970 s. The operative mortality in young patients between 1970 and 1980 was $7 \%$ compared with $1.2 \%$ between 1981 and 1991 in Baltimore. ${ }^{2}$ The operative mortality stated in this report was $3.9 \%$, which is slightly higher than other reports around this period. ${ }^{3}$

Investigation and treatment of coronary artery disease in women has been a high profile topic in recent years. ${ }^{4}$ In this report $11 \%$ of those operated on were women none of whom had an exercise test. In a more recent series $20 \%$ of patients operated on were women although this cannot be extrapolated to the population of West Lothian. ${ }^{5}$ There was no difference in outcome of women in West Lothian compared with their male counterparts.

The importance of checking cholesterol preoperatively was of disputed importance at the time of the study. Only $14 \%$ of those operated on had their cholesterol checked com- 
pared with over $80 \%$ in 1986 in a series from New South Wales. These authors also reported an increase in the use of lipid regulating drugs from $2 \%$ to $37 \%$ in CABG patients from 1986 to $1994 .^{6}$ Studies of angiographic progression in bypass grafts and native arteries have shown conflicting results in determining cholesterol as a risk factor. ${ }^{78}$ Late survival of CABG patients in Helsinki was not influenced by cholesterol values. ${ }^{9}$

No doctor likes to refer patients for procedures that may shorten their lives. This report does not compare medical treatment with surgical treatment although the proportion of patients with single and double vessel disease were similar to the early trials. ${ }^{1}$ Survival statistics for the patients of West Lothian were similar at five years to those having surgery in these trials but slightly higher at 10 years.

It is interesting that age at operation was not a predictor of survival and that no one over 70 years of age was operated on. The elderly are now not so disadvantaged with $15-33 \%$ of all operations in more recent series being carried out on patients $70-80$ years old ${ }^{10}{ }^{11}$ and an increase of over $200 \%$ in operations for men over 70 years between 1984 and 1989 in another centre. ${ }^{5}$ There is evidence that outcome beyond the perioperative period is not influenced by age ${ }^{10}$ although people aged over 80 in Missouri did less well. ${ }^{12}$

The prognostic indicators of poor left ventricular function and extensive disease were borne out with all patients with poor left ventricular function dying (one in his eleventh year after operation). Abnormal exercise tolerance tests, severe symptoms, and number of grafts pointed to increased likelihood of cardiac death.

Around $40 \%$ of those operated on were asymptomatic at 10 years. Not surprisingly the patients with limited disease were more likely to be asymptomatic or have a further revascularisation procedure. It is also interesting that those who had a repeat procedure were signifi- cantly younger than those survivors who had angina but no repeat procedure. This is similar to experience in Atlanta where $31 \%$ of survivors at 12 years had had a repeat procedure. $^{13}$

The results from a single district are not noticeably different from the reported experience from randomised trials of surgical versus medical treatment. Relief of symptoms remains the indication for surgery. Patients and relatives should not be misled that this procedure confers longevity.

1 Yusuf S, Zucker D, Beduzzi P, Fisher LD, Takard T, Kennedy JH, et al. Effect of coronary artery bypass graft surgery on survival: overview of 10-year results from randomised trials by the Coronary Artery Bypass Graft Surgery Trialists Collaboration. Lancet 1994;344:563-70.

2 Zehr KJ, Lee PC, Poston RS, Gillinov AM, Greene PS, Cameron DE. Two decades of coronary artery bypass graft surgery in young adults. Circulation 1994;90:133-9.

3 Coronary Artery Surgery Study (CASS) principal investigators and associates. CASS: a randomised trial of coronary bypass surgery. Circulation 1983;68:939-50.

4 Petticrew M, McKee M, Jones J. Women and coronary artery surgery - are women discriminated against? $B M \mathcal{F}$ 1993;306:1164-6.

5 Platt GH, Svenson LW, Woodhead SE. Coronary artery bypass grafting in Alberta from 1984 to 1989 . Can $\mathcal{F}$ Cardiol 989;9:621-4

6 Simons LA, Simons J, Parfitt A. Coronary risk factors 6-12 months after coronary artery bypass grafting. Comparison of surveys in 1986, 1990 and 1994. Med F Aust 1994;161: 536-7.

7 Bourassa MG, Enjalbert M, Campeau L, Lesperance J. Progression of atherosclerosis in coronary arteries and bypass grafts; ten years later. Am $\mathcal{F}$ Cardiol 1984;53:102-7.

8 Alderman EL, Corley SD, Fisher LD, Chaitman BR, Faxon $\mathrm{DP}$, Foster ED, et al. Five year angiographic follow-up of factors associated with progression of coronary artery disease in the coronary artery surgery study. $\mathcal{F} \mathrm{Am}$ Coll Cardiol 1993;22:1141-54.

9 Mattila P, Vento A, Ristikankare M, Matilla S. Multivariate analysis of operative mortality and late outcome after coronary artery bypass surgery. $\mathcal{F}$ Cardiovasc Surg 1990;31: 220-4.

10 King KB, Clark PC, Norsen LH, Hicks GL Jr. Coronary artery bypass graft surgery in older women and men. Am $\mathcal{F}$ artery bypass graft surger
Crit Care 1992;1:283.

11 Negre G, Nangou P, Boennec M, el Abadi S, Francois F, Bapral M, et al. Coronary surgery in patients aged 70 years and older. 65 cases. Presse Med 1991;20:1429-33.

12 Peigh PS, Swartz MT, Vaca KJ, Lohmann DP, Naunheim KS. Effect of advancing age on cost and outcome of coronary artery bypass grafting. Ann Thorac Surg 1994;58: 1362-6.

13 Weintraub WS, Jones EL, Craver JM, Guyton RA. Frequency of repeat coronary bypass or coronary angioplasty after coronary artery bypass graft using saphenous vein grafts. Am f Cardiol 1994;73:103-12. 